\section{References}

1. Moon MR, Stinson EB, Miller DC. Surgical treatment of endocarditis. Prog Cardiovasc Dis. 1997;40:239-64.

2. Arbulu A, Asfaw S. Management of infective endocarditis: seventeen years' experience. Ann Thorac Surg. 1987;43:144-9.

3. Rao V, Van Arsdell GS, David TE, Azakie A, Williams WG. Aortic valve repair for adult congenital heart disease: a 22-year experience. Circulation. 2000;102(19 Suppl 3):III40-3.

4. Moon MR, Miller DC, Moore KA, Oyer PE, Mitchell RS, Robbins
$\mathrm{RC}$, et al. Treatment of endocarditis with valve replacement: the question of tissue versus mechanical prosthesis. Ann Thorac Surg. 2001;71:1164-71.

5. Gordon SM, Serkey JM, Longworth DL, Lytle BW, Cosgrove DM. Early onset of prosthetic valve endocarditis: the Cleveland Clinic experience 1992-1997. Ann Thorac Surg. 2000;69:1388-92.

6. Grunkemeier GL, Hui-Hua L. Epidemiology and risk factors for prosthetic valve endocarditis. In: Vlessis AA, Bolling S, editors. Endocarditis: a multidisciplinary approach to modern treatment. Armonk, NY: Futura Publishing; 1999. p. 85-103.

\title{
Initial experience with a stentless porcine bioprosthesis for right ventricular outflow tract reconstruction in children
}

\author{
Luca A. Vricella, MD, Michael A. Coady, MD, and Michael D. Black, MD, Stanford, Calif
}

$\mathrm{P}$ ostoperative pulmonary regurgitation and stenosis still remain major determinants of long-term outcome in children requiring right ventricular outflow tract (RVOT) reconstruction.

Because of relatively low right-sided pressures, mechanical valves are at high risk for thrombosis, and long-term anticoagulation is disadvantageous in pediatric patients for obvious reasons. ${ }^{1}$ Because of accelerated calcification, bioprosthetic valves are, on the other hand, likely to undergo structural valve deterioration in younger patients. ${ }^{2}$

The use of a stentless valve design, with improved shear stress on the valve leaflets, might prevent early valvular calcification. The Toronto stentless porcine valve (SPV; St Jude Medical, Inc, St Paul, Minn) incorporates a flexible Dacron ring with lack of an accompanying aortic wall. We hypothesized that these distinguishing characteristics might allow for improved long-term function when used in RVOT reconstruction in children.

\section{Clinical Summary}

Nine patients ( 8 male patients and 1 female patient) born with tetralogy of Fallot underwent RVOT reconstruction with Toronto SPVs between March 1998 and July 2001. Mean age and weight were, respectively, 11.2 years (range, 4-17 years) and $41.6 \mathrm{~kg}$

\footnotetext{
From the Division of Pediatric Cardiac Surgery, Lucile Packard Children' Hospital at Stanford, Stanford University School of Medicine, Stanford, Calif.

Received for publication Dec 7, 2002; accepted for publication Aug 27 2002.

Address for reprints: Michael D. Black, MD, Pediatric Cardiac Surgery, Lucile Packard Children's Hospital, Stanford University School of Medicine, Stanford, CA 94305-5407 (E-mail: Michael.black@leland.stanford. edu).

J Thorac Cardiovasc Surg 2003;125:727-8

Copyright $\odot 2003$ by The American Association for Thoracic Surgery $0022-5223 / 2003 \$ 30.00+0$

doi: $10.1067 / \mathrm{mtc} .2003 .22$
}

(range, 15.2-83.1 kg). Preoperative patient characteristics and surgical indications are summarized in Table 1. All but one procedure were reoperative, with surgical indications being RVOT stenosis $(n=4)$ or pulmonary insufficiency $(n=5)$. Intraoperative transesophageal echocardiography was performed in all patients, and transthoracic echocardiograms were obtained at various intervals

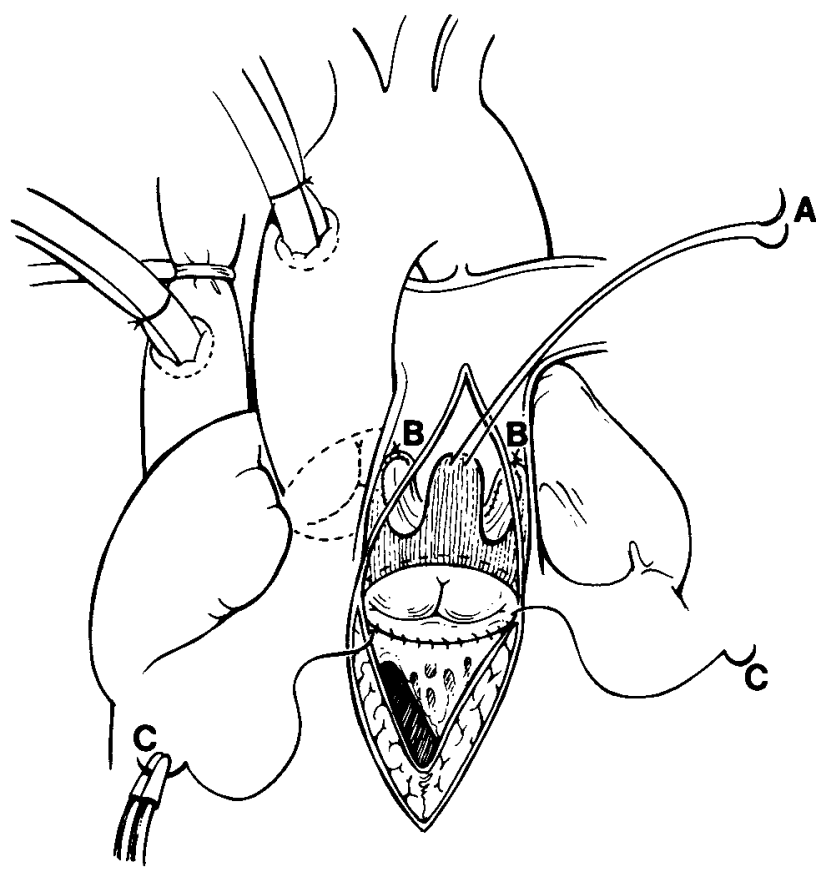

Figure 1. Insertion of an SPV in the subannular position within the RVOT before patch arterioplasty: $A$, mattress suture securing the anterior SPV commissural post to the RVOT patch; B, sutures spacing the posterior posts at $120^{\circ}$ distance to protect the right and left pulmonary ostia; $C$, continuous proximal suture. The anterior $120^{\circ}$ of the suture line are passed transversely across the RVOT patch. 
TABLE 1. Preoperative characteristics, operative procedures, and follow-up echocardiography

\begin{tabular}{|c|c|c|c|c|c|}
\hline Patient no. & $\begin{array}{l}\text { Age } \\
\text { (y) }\end{array}$ & $\begin{array}{l}\text { Weight } \\
\text { (kg) }\end{array}$ & $\begin{array}{l}\text { SPV size } \\
(\mathrm{mm})\end{array}$ & Additional procedures performed & $\begin{array}{l}\text { Length of follow-up; result of } \\
\text { latest echocardiogram }\end{array}$ \\
\hline 1 & 7 & 22.8 & 22 & RVOT patch & 38 mo; no PI, RVOT PSG 25 mm Hg \\
\hline 2 & 4 & 15.2 & 19 & VSD closure, RVOT patch & 34 mo; no PI, RVOT PSG 25 mm Hg \\
\hline 3 & 17 & 83.1 & 29 & RVOT patch & $18 \mathrm{mo}$; trace PI, RVOT PSG $19 \mathrm{~mm} \mathrm{Hg}$ \\
\hline 4 & 7 & 23.0 & 27 & VSD closure & $11 \mathrm{mo}$; trace PI, RVOT PSG $19 \mathrm{~mm} \mathrm{Hg}$ \\
\hline 5 & 13 & 40.2 & 29 & Intraoperative branch PA stenting & $11 \mathrm{mo}$; mild PI, RVOT PSG $13 \mathrm{~mm} \mathrm{Hg}$ \\
\hline 6 & 9 & 24.0 & 27 & RVOT patch & $10 \mathrm{mo}$; trace PI, RVOT PSG $15 \mathrm{~mm} \mathrm{Hg}$ \\
\hline 7 & 16 & 81.4 & 29 & RVOT patch & $6 \mathrm{mo}$; trace PI, RVOT PSG $19 \mathrm{~mm} \mathrm{Hg}$ \\
\hline 8 & 12 & 32.0 & 29 & VSD closure, RVOT patch & 2 mo; no PI, RVOT PSG 6 mm Hg \\
\hline 9 & 16 & 53.0 & 29 & $\begin{array}{l}\text { VSD closure, aortic-tricuspid } \\
\text { valve repair, RVOT patch }\end{array}$ & 2 mo; trace PI, RVOT PSG $21 \mathrm{~mm} \mathrm{Hg}$ \\
\hline
\end{tabular}

$P I$, Pulmonary insufficiency; VSD, ventricular septal defect; $P S G$, peak systolic gradient; $P A$, pulmonary artery.

after discharge. No antiaggregant or anticoagulation therapy was used. Mean follow-up was 14.5 months (range, 2-38 months).

Prosthetic valve diameter ranged between 19 and $29 \mathrm{~mm}$ (mean, $27 \mathrm{~mm}$ ). Mean cardiopulmonary bypass time was 165 minutes. Three patients underwent additional ventricular septal defect repair, and 7 required pericardial RVOT patch augmentation. One patient required intraoperative bilateral branch pulmonary artery stenting and one aortic and tricuspid valve repair. All patients were extubated in the operating room. Mean postoperative hospital stay was $2.6 \pm 0.8$ days. No structural valve deterioration was evident at the latest echocardiographic examination, and mean postoperative peak systolic RVOT gradient was $18 \pm 6 \mathrm{~mm} \mathrm{Hg}$. There were no early or late postoperative complications or deaths, and no intermediate-term reintervention was necessary for valverelated complications.

\section{Comment}

Pulmonary valve replacement in children still remains a difficult surgical challenge because no ideal valve substitute exists. The Toronto SPV bioprosthesis offers a better hemodynamic profile in the aortic position than stented valves, resembling the hemodynamic characteristics of an aortic homograft. At least in the aortic position, stentless valves appear to outperform stented bioprostheses, and durability beyond 10 years in a substantial number of patients is seen. ${ }^{3}$

Most of the intermediate-term data thus far acquired on this particular bioprosthesis derives from aortic valve replacement and not RVOT reconstruction. In the pulmonary circuit, where hemodynamic stress is not as marked as in the left ventricular outflow tract, long-term durability for SPVs should be expected.

Several points should be made with regard to the technique of valve implantation (Figure 1). Orientation of the valve, with 1 anterior and 2 lateral posts, is important in avoiding obstruction of the origin of the branch pulmonary arteries. The commissural posts should ideally be spaced at $120^{\circ}$ intervals. Because of the more modest shear stress to which the valve is subject within the RVOT, the suture line should be continuous along the entire proximal circumference of the sewing ring, rather than along the commissural posts, as usually performed while implanting SPVs in the aortic position. Lastly, should an arterioplasty be necessary, a pericardial patch can be easily incorporated into the suture line because it runs along the anterior portion of the bioprosthesis. This in turn allows for insertion of a prosthesis with optimal diameter.
When compared with other currently available mechanical prostheses or other bioprosthetic valves, the SPV has several advantages:

1. The lack of need for anticoagulation is intuitively a major advantage when considering the use of the valve in pediatric patients.

2. The low profile of the SPV and its pliability facilitate insertion at various RVOT levels, either in the annular on infra-annular position.

3. When compared with homografts, SPVs might disclose less incidence of stenosis at long-term follow-up. The SPV is in fact devoid of porcine aortic wall, which has been found to predispose to premature dystrophic calcification in the animal model. ${ }^{4}$

4. In the unlikely event of progressive valvular stenosis, percutaneous balloon valvotomy might be an option. ${ }^{5}$

This initial experience with SPVs in reconstruction of an RVOT in children has shown encouraging clinical results. With increased follow-up, we speculate that insertion of an SPV might be appropriate in older children, in whom late degeneration of homografts (valvular or conduit related) remains predictable. When the child has adequate connection between the right ventricle and the pulmonary artery, the SPV might represent a comparable alternative to currently available options. ${ }^{6}$

\section{References}

1. Rosti L, Murzi B, Colli AM, Festa P, Redaelli S, Frigida A. Pulmonary valve replacement: a role for mechanical prosthesis? Ann Thorac Surg. 1998;65:889-90.

2. Fukada J, Morishita K, Komatsu K, Abe T. Influence of pulmonary position on durability of bioprosthetic heart valves. Ann Thorac Surg. 1997;64:1678-80.

3. David TE, Puschmann R, Ivanov J, Bos J, Armstrong S, Feindel C, et al. Aortic valve replacement with stentless and stented porcine valves: a case-matched study. J Thorac Cardiovasc Surg. 1998;116:236-41.

4. Schoof PH, Hazekamp MG, van Krieken HH, Huysmans HA. Pulmonary root replacement with the freestyle stentless aortic xenograft in growing pigs. Ann Thorac Surg. 1998;65:1726-9.

5. Herrmann HC, Hill JA, Krol J, Pepine CJ. Effectiveness of percutaneous balloon valvulplasty in adults with pulmonary valve stenosis. Am J Cardiol. 1991;68:1111-3.

6. Jin XY, Gibson DG, Yacoub MH, Pepper JR. Perioperative assessment of aortic homograft, Toronto stentless valve, and stented valve in the aortic position. Ann Thorac Surg. 1995;60:S395-401. 